\title{
Photostriction in Lead Lanthanum Zirconate Titanate Ceramics Enhanced by the Additive Effect
}

\author{
Kazuhiro NONAKA, Morito AKIYAMA, Tsuyoshi HAGIO, Akira TAKASE*, Toshiyuki BABA**, \\ Keisuke YAMAMOTO**, Makoto HIRAOKA** and Hirotaka ITO** \\ Inorganic Composite Materials Department, Kyushu National Industrial Research Institute, 807-1, Shuku-machi, Tosu-shi, Saga 841-0052 \\ *Materials Chemistry Department, Kyushu National Industrial Research Institute, 807-1, Shuku-machi, Tosu-shi, Saga 841-0052 \\ **Fundamental Research Department, Central Research Laboratory, Mitsubishi Cable Industries, Ltd., \\ 4-3, Ikejiri, Itami-shi, Hyogo 664-0027
}

\author{
加成的効果によって增強されたチタン酸ジルコン酸ランタン鉛セラミックスの光歪み

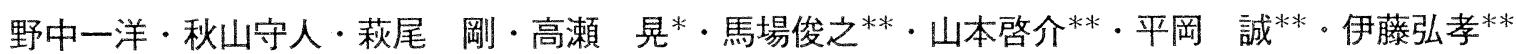 \\ 九州工業技術研究所無機複合材料部，841-0052 佐賀県鳥栖市宿町 807-1 \\ *九州工業技術研究所材料化学部, 841-0052 佐賀県鳥栖市宿町 807-1 \\ **三菱電線工業 (株) 中央研究所基礎技術研究部，664-0027 兵庫県伊丹市池尻 4-3
}

\begin{abstract}
$\left(\mathrm{Pb}_{0.97}, \mathrm{La}_{0.03}\right)\left(\mathrm{Zr}_{0.52}, \mathrm{Ti}_{0.48}\right)_{1-0.03 / 4} \mathrm{O}_{3}$ ceramics doped with $0-10 \mathrm{~mol} \%$ Ta were sintered at $1200^{\circ} \mathrm{C}$ for $2 \mathrm{~h}$ and then heat-treated in nitrogen at $900^{\circ} \mathrm{C}$ for $1 \mathrm{~h}$ to investigate the change in the photostrictive response upon illumination with wavelength of $300-400 \mathrm{~nm}$. Before the heat treatment in nitrogen, both photovoltaic current and voltage were increased by doping with Ta, revealing maxima around $1.5 \mathrm{~mol} \%$ of doped Ta. A very similar change upon doping with Ta was observed in piezoelectric properties such as electromechanical coupling factor $\left(k_{33}\right)$, strain constant $\left(d_{33}\right)$ and dielectric constant. On the other hand, the heat treatment in nitrogen heightened the photovoltaic response, on the whole, regardless of the amount of doped Ta, but scarcely affected the piezoelectric parameters. Due to an additive effect of the doping with Ta and the nitrogen-treatment, the photovoltaic properties were further enhanced and hence the photostriction response was confirmed to be markedly improved. [Received November 13, 1997; Accepted March 30, 1998]
\end{abstract}

Key-words : Photostriction, Lead lanthanum zirconate titanate ceramics, Additive effect, Heat treatment, Impurity doping

\section{Introduction}

Photostriction materials convert light directly to physical movement. ${ }^{1)-4)}$ The mechanism of photostriction is explained by superposition of the photovoltaic effect and piezoelectricity. When homogeneous noncentrosymmetric materials such as ferroelectric single crystals and polarized ferroelectric ceramics are uniformly illuminated, a high voltage which considerably exceeds band gap energies is generated without external fields. ${ }^{5)}$ In certain ferroelectrics, photovoltage is of the order of kilovolts to megavolts per centimeter. At the same time a mechanical strain is induced along particular directions in the ferroelectrics by means of the piezoelectric effect. This property enables the ferroelectrics to be used as photo-driven actuators, capable of wireless remote control and hence suitable for application in devices that are difficult to connect to power supply wires. These optical actuators have been receiving a considerable amount of attention in fields related to micromechanisms, ultrahigh vacuum and space technologies. Optical actuators are also anticipated as being used as driving components in electromagnetic-noise-free systems which use optical control. Furthermore, the photostriction effect has recently been applied in trials conducted for fabricating a photophonic device, intended for transforming light directly into sound on the basis of mechanical vibration induced upon intermittent illumination. ${ }^{2)}$

The photostriction effect is studied mostly for ferroelectric polycrystalline materials from a practical application point of view; lead lanthanum zirconate titanate (PLZT) ceramics are typical photostriction materials owing to their relatively high photostrictive efficiency and ease of preparation. ${ }^{6}$ ) In these studies it is shown that one of the most significant requirements is improvement of slow response speed of the PLZT ceramics. The required degrees of enhancement are thought to be different in individual applications : for example, it is reported that the mechanical resonance frequency of the photostrictive PLZT bimorph-type devices as photo-acoustic components ${ }^{2)}$ needs to be increased at least two to three fold to facilitate easy hearing of the sound. ${ }^{7)}$ To improve the photostriction effect many factors such as material composition, microstructures, material preparation method, and impurity doping have been investigated.2),3)

We have reported the effects of heat treatments in different atmospheres ${ }^{8)}$ and of doping of various impurity elements, ${ }^{9}$ as well as their combined effects, ${ }^{10}$ on the photovoltaic properties of PLZT ceramics. Both photovoltaic current and photovoltage are found to be markedly increased by the heat treatment in nitrogen. Concerning the doping effects, we found a clear relationship between the photovoltaic response and the kind of doped ions such as donor, acceptor, easily variable valency, and remainders. In order to introduce doping effects, sample preparation considering charge compensation for electroneutrality is found to be critical. The photovoltaic response is increased by doping with donor ions such as Ta and W.11) It is also clarified that additivity holds for the effect of nitrogen treatment and that of donor doping. We investigated the photovoltaic response for the samples doped with various amounts of $\mathrm{Ta}$, before and after the nitrogen treatment. ${ }^{10)}$ Before the nitrogen treatment, both the photovoltaic current and photovoltage exhibited maxima for around $1.5 \mathrm{~mol} \%$ of doped Ta. Similar changes in photovoltaic behavior with various doping amounts of $\mathrm{Ta}$ were also observed in the nitrogen-treated sample. However, the values of photovoltaic current and 
photovoltage were, on the whole, notably increased in comparison with those of the doped samples pretreated in nitrogen. We concluded from this result that the nitrogen treatment and the doping with Ta contribute to the photovoltaic effect through different mechanisms, which were discussed in detail in a previous paper. ${ }^{10)}$

The present paper describes the improvement of photostriction in PLZT ceramics caused by the additive effect of the nitrogen treatment and the doping with Ta. Piezoelectric parameters and photostrictive responses were measured in various samples and the obtained results were evaluated with those of the photovoltaic measurements ${ }^{10}$ previously reported.

\section{Experimental procedure}

\subsection{Sample preparation}

Samples of $\left(\mathrm{Pb}_{0.97}, \mathrm{La}_{0.03}\right)\left(\mathrm{Zr}_{0.52}, \mathrm{Ti}_{0.48}\right)_{1-0.03 / 4} \mathrm{O}_{3}$ (PLZT $(3 / 52 / 48))$ ceramics doped with various amounts of Ta were prepared by the conventional solid-state reaction process. The basic composition of PLZT $(3 / 52 / 48)$ has been reported to show the highest photostrictive efficiency. ${ }^{6}$ ) The detailed preparation technique was described in an earlier paper. ${ }^{12)}$ To ensure electroneutrality on doping, the basic composition was modified to compensate for an increase in positive charge due to $\mathrm{Ta}$ by creating $\mathrm{Pb}$ vacancies according to the amount of doped Ta. The amounts of Ta were expressed in terms of molar concentrations of $\mathrm{Ta}$ relative to the total amounts of $\mathrm{Zr}$ and $\mathrm{Ti}$ whose initial molar ratio of $52 / 48$ was fixed for all samples. One face of the samples was optically polished as an illumination plane. These samples were cut into $3 \times 3 \times 8 \mathrm{~mm}^{3}$ bars. To investigate the effect of heat treatment in nitrogen, they were placed in a magnesia crucible and then heat-treated in nitrogen at $900^{\circ} \mathrm{C}$ for $1 \mathrm{~h}$. Before the heat treatment in nitrogen, the samples were also examined for comparison. Silver electrodes were fired onto the $3 \times 3 \mathrm{~mm}^{2}$ faces for the piezoelectric measurements and onto the $3 \times 8 \mathrm{~mm}^{2}$ faces for the photostrictive measurements at $480^{\circ} \mathrm{C}$. Samples were poled in silicon oil at $150^{\circ} \mathrm{C}$ by applying a dc field of 2 $\mathrm{kV} / \mathrm{mm}$ for $30 \mathrm{~min}$.

\subsection{Measurements}

An ultrahigh-pressure mercury lamp (500 W) was used as the light source. Using optical glass filters, light with wavelength ranging from 300 to $400 \mathrm{~nm}$ with a maximum strength around $365 \mathrm{~nm}$ was obtained and illuminated on the optically polished $3 \times 8 \mathrm{~mm}^{2}$ face of the sample. Piezoelectric parameters were measured with a vector impedance analyzer (HP-4392A). The photostriction was recorded using a strain gauge attached to the bottom plane opposite to the illuminating surface.

\section{Results and discussion}

\subsection{Piezoelectric properties}

Figure 1 shows the variation in piezoelectric parameters with heat treatment in nitrogen for the samples doped with various amounts of $\mathrm{Ta}$. In the samples pretreated in nitrogen, the values of $k_{33}, d_{33}$ and dielectric constant were increased by doping with $\mathrm{Ta}$ and showed maxima for around $1.5 \mathrm{~mol} \%$ of doped Ta. This increase in the piezoelectric parameters is well-known as the softening effect of donor doping. ${ }^{13)}$ Very similar results were obtained from the nitrogen-treated samples. Before and after the nitrogen-treatment, these piezoelectric parameters were found to change negligibly, in contrast to the notable change in the photovoltaic properties mentioned above. Prisedsky ${ }^{14)}$ studied the effect of oxygen nonstoichiometry on piezoelectric properties of a PZT material and reported that the lowering of oxygen partial pressure during heat treatment of nondoped sample produces an effect similar to that of doping with donor ions, but such treatment does not give as large an effect as that of impurity doping.

\subsection{Photostrictive response}

The photostriction can be expressed by $x(t)=d_{33} E\{1-\exp (-t / R C)\}$

where $x(t)$ is the photostriction, $E$ the saturated photovoltaic field, $t$ the time, $R$ the resistance under illumination, and $C$ the capacitance. ${ }^{1,3), 4)}$ An increase in the photovoltaic current decreases the values of $R$ and contributes to the overall response. It is also reported that the values of $C$ are little affected by illumination and depend mostly on the dielectric constant. ${ }^{4)}$ Then, we also estimated the values of $C$ from the dielectric constant shown in Fig. 1. When the sample is optically irradiated, photostriction occurs progressively following $R C$ as the time constant, in order to achieve the maximum strain of $d_{33} E$.

Figure 2 shows the variation in the time constant, $R C$ with heat treatment in nitrogen for the samples doped with various amounts of Ta. The values of $R$ were calculated from the ratio of the photovoltage and the photovoltaic current previously reported. ${ }^{10)}$ Before the nitrogen-treatment,
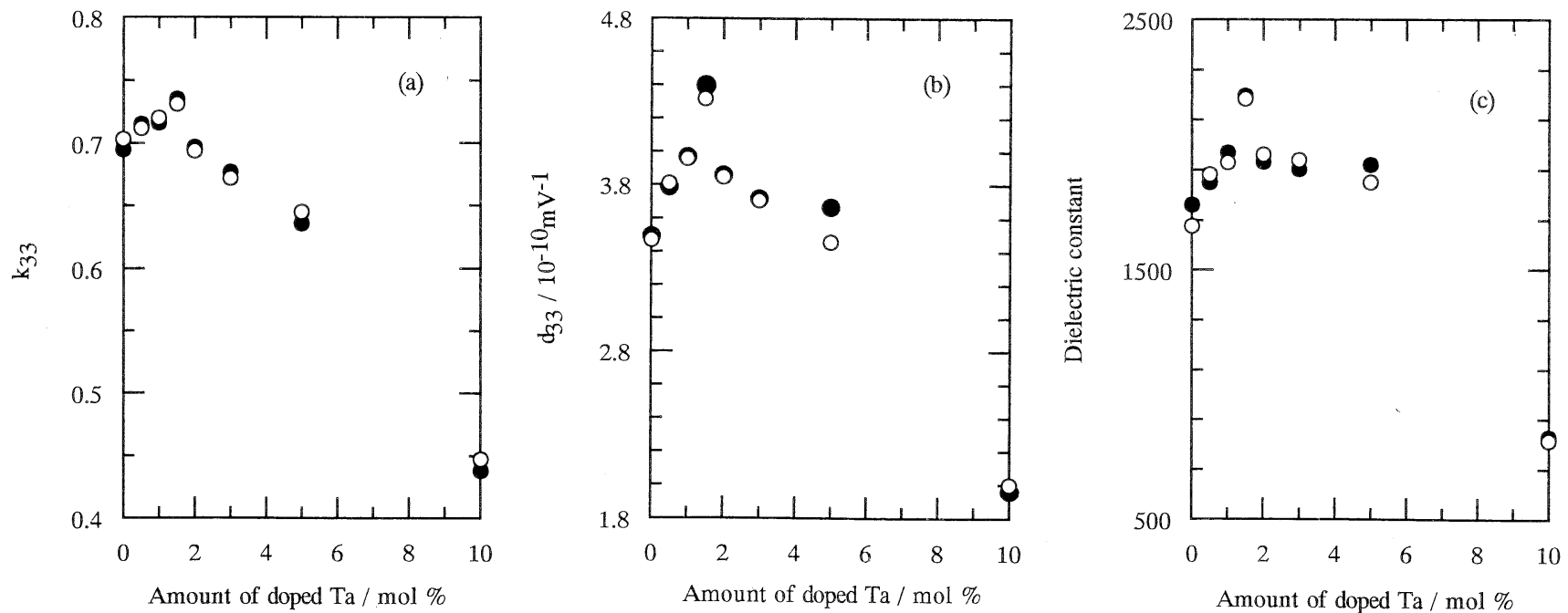

Fig. 1. Electromechanical coupling factor $k_{33}$ (a), piezoelectric strain constant $d_{33}$ (b), and dielectric constant (c) as a function of amounts of doped Ta in various PLZT ceramics samples. The open and closed symbols, respectively, denote pretreated and heat-treated samples in nitrogen at $900^{\circ} \mathrm{C}$ for $1 \mathrm{~h}$. Illumination intensity: $40 \mathrm{~mW} \cdot \mathrm{cm}^{-2}$. 


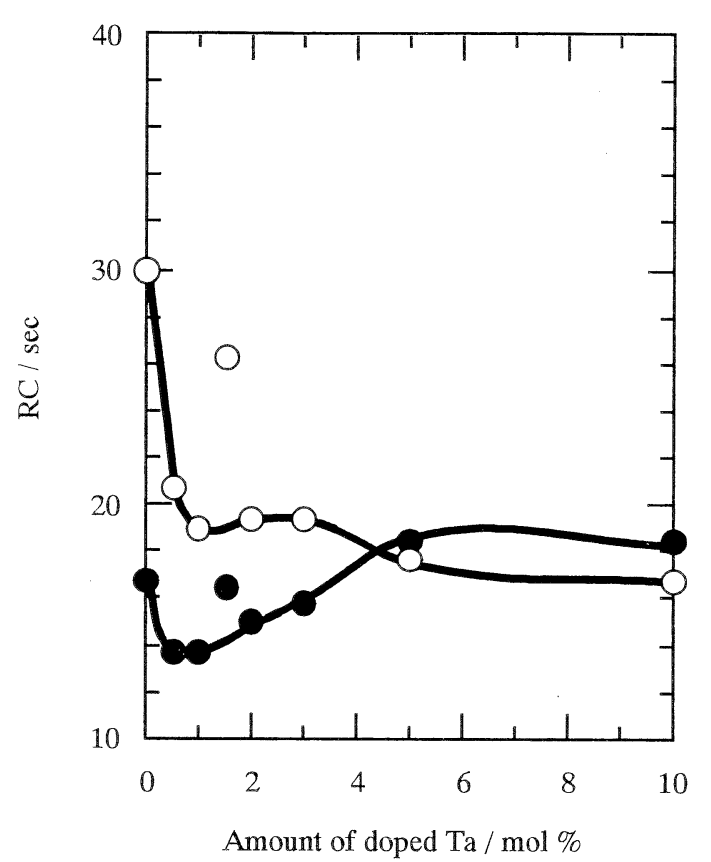

Fig. 2. Variation in the time constant $R C$ with heat treatment in nitrogen at $900^{\circ} \mathrm{C}$ for $1 \mathrm{~h}$ for the PLZT ceramics doped with various amounts of Ta. Symbols are the same as those shown in Fig. 1. Illumination intensity: $40 \mathrm{~mW} \cdot \mathrm{cm}^{-2}$.

the samples showed minimum of $R C$ around $1 \mathrm{~mol} \%$ of doped Ta. Above $3 \mathrm{~mol} \%$ of doped Ta, $R C$ again decreased slightly due to the lower densities of the samples. After the nitrogen-treatment, the values of $R C$ further decreased and showed a minimum value similarly around $1 \mathrm{~mol} \%$ of doped Ta. The value of $R C$ was thus found to be lowered due to such a combined effect resulting in an improved photostriction response. By comparing the value of $R C$ in the sample doped with $1 \mathrm{~mol} \%$ Ta before the nitrogen-treatment with that in the nondoped sample after the nitrogen-treatment, the latter was noted to be fairly low. It was thus found that the degree of contribution toward lowering the value of $R C$ by the nitrogen-treatment was somewhat larger than that by the doping with Ta.

Figure 3 shows the photostrictive response for the various samples. In this figure, photostriction curves calculated from Eq. (1) were involved. The parameters used for the calculation are summarized in Table 1, wherein the actually measured and the calculated strains were also given. Before the nitrogen-treatment, the sample doped with Ta revealed an increased photostrictive response compared with the nondoped sample. We also confirmed that the photostrictive response can be further enhanced by the combined effect of the doping with $\mathrm{Ta}$ and the nitrogentreatment. Thereby, the maximum strain became $60 \%$ larger than that in the nondoped sample. It should be also noted that by the combined effect, a striction rate roughly 4 times higher than that in the nondoped sample can be obtained at strains of up to $0.6 \times 10^{-4}$. This result is supposed to be useful for the application of PLZT ceramics in photophonic devices because they require quick response rather than large strains.

The strains actually observed in the initial part are found to agree well with those calculated from Eq. (1) in each sample, but later the measured strains gradually became somewhat larger than the calculated values. This result suggests that the values of $d_{33} E$ for the measured strain curves are larger than those calculated with the parameters given in Table 1 : to clearly explain the reasons for this difference

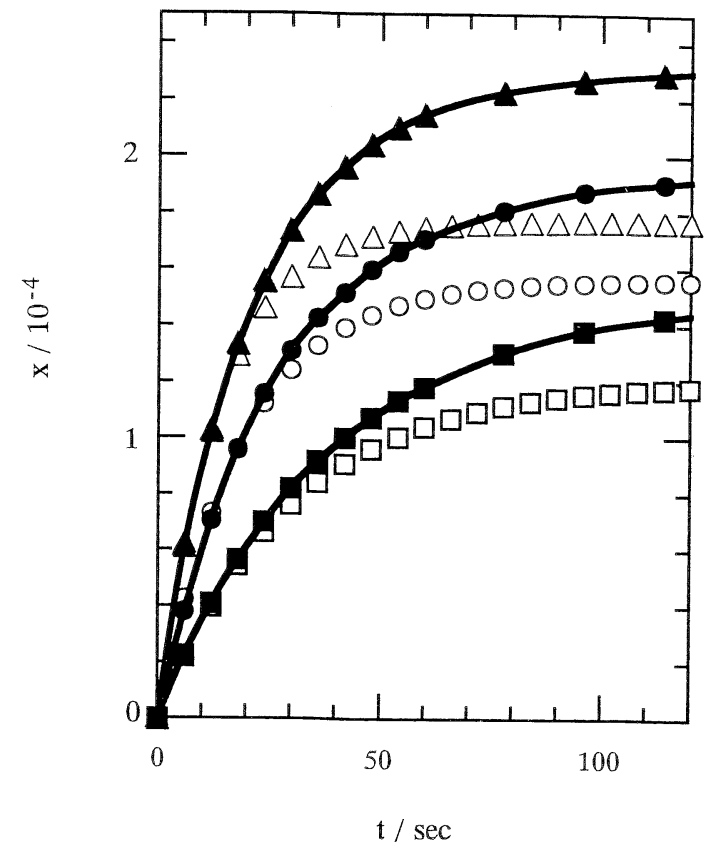

Fig. 3. Photostriction $x$ as a function of illuminating time $t$ in the nondoped samples $(\square, \mathbf{Q})$, samples doped with $1 \mathrm{~mol} \% \mathrm{Ta}(O$, -), and samples doped with 1 mol\% Ta and subsequently heattreated in nitrogen at $900^{\circ} \mathrm{C}$ for $1 \mathrm{~h}(\triangle, \boldsymbol{\Delta})$. The open and closed symbols, respectively, denote the data calculated using Eq. (1) and those actually measured. Illumination intensity: $40 \mathrm{~mW} \cdot \mathrm{cm}^{-2}$.

Table 1. Photostrictive Parameters and Measured and Calculated Strains for the Various Samples

\begin{tabular}{|c|c|c|c|c|c|}
\hline Sample & $\mathrm{d}_{33} / 10^{-10} \mathrm{mV}^{-1}$ & $\mathrm{E} / \mathrm{MVm}^{* 1}$ & $\mathrm{RC} / \mathrm{sec}$ & $\begin{array}{c}\mathrm{x}_{\text {meas }}^{* 2} / 10^{-4} \\
\left(\mathrm{r}_{\mathrm{a}}\right)^{* 3}\end{array}$ & $\begin{array}{c}\mathrm{x}_{\mathrm{cal}}^{* 2} / 10^{-4} \\
\left(\mathrm{r}_{\mathrm{b}}\right)^{* 3}\end{array}$ \\
\hline nondoped & 3.47 & 0.345 & 29.9 & $\begin{array}{l}1.43 \\
(1)\end{array}$ & $\begin{array}{l}1.17 \\
(1)\end{array}$ \\
\hline $\begin{array}{l}\text { doped with } \\
1 \mathrm{~mol} \% \mathrm{Ta}\end{array}$ & 3.96 & 0.396 & 18.9 & $\begin{array}{l}1.90 \\
(1.3)\end{array}$ & $\begin{array}{l}1.56 \\
(1.3)\end{array}$ \\
\hline $\begin{array}{l}\text { doped with } \\
1 \text { mol\% Ta } \\
\text { \& nitrogen-t }\end{array}$ & -treated 3.97 & 0.446 & 13.7 & $\begin{array}{l}2.29 \\
(1.6)\end{array}$ & $\begin{array}{l}1.77 \\
(1.5)\end{array}$ \\
\hline
\end{tabular}

$* 1$. See ref. 9 for the used data.

*2. $\mathrm{x}_{\text {meas }}$ and $\mathrm{x}_{\mathrm{cal}}$, respectively, denote the measured and the calculated strains from eq(1) at $114 \mathrm{sec}$ of illuminating time.

*3. $\mathrm{r}_{\mathrm{a}}$ and $\mathrm{r}_{\mathrm{b}}$, respectively, represent the ratios of $\mathrm{x}_{\text {meas }}$ and of $\mathrm{x}_{\text {cal }}$ among the samples.

a further experiment is needed. Considering the strain ratios among the samples, however, the ratios $\left(r_{\mathrm{a}}\right)$ estimated from the measured strain data $\left(x_{\text {meas }}\right)$ are in close accordance with those $\left(r_{\mathrm{b}}\right)$ estimated from the calculated strain data $\left(x_{\text {cal }}\right)$ for each sample as shown in Table 1 ; the ratios are expressed in terms of relative strain values when $x_{\text {meas }}$ and $x_{\text {cal }}$ in the nondoped sample (pretreated in nitrogen) are the units. This result indicates that the increase in the photostrictive response actually measured implies the real improvement, which is expected from the effects of the nitrogen-treatment and of the doping of Ta, as well as from their combined effect. 


\section{Summary}

We have investigated the photostriction response in the PLZT ceramics doped with various amounts of Ta and subsequently heat-treated in nitrogen. Both photovoltaic and piezoelectric properties were improved by doping with Ta. On the other hand, nitrogen-treatment heightened the photovoltaic response, but scarcely affected the piezoelectric parameters. By the combined effect of doping with Ta and nitrogen-treatment, the photostriction response was confirmed to be markedly enhanced.

\section{References}

1) P. S. Brody, Ferroelectrics, 50, 27-32 (1983).

2) S.-Y. Chu and K. Uchino, Ferroelectrics, 174, 185-96 (1995).

3) P. Poosanaas, A. Dogan, A. V. Prasadarao, S. Komarneni and K. Uchino, J. Electroceramics, 1, 105-11 (1997).

4) T. Nakada, D.-H. Cao, Y. Morikawa, M. Kimura and C.-Y. Hsien, Nippon Kikaigakkai Ronbunshu, C59, 2470-76 (1993).

5) V. M. Fridkin, "Photoferroelectrics," Solid State Sciences, Vol. 9, Ed. by M. Cardona, P. Fulde and H.-J. Queisser, Spr-
inger-Verlag, New York (1979) pp. 85-113.

6) K. Uchino, M. Aizawa and S. Nomura, Ferroelectrics, 64 , 199-208 (1985).

7) R. F. Service, Science, 266, 1807-08 (1994).

8) K. Nonaka, M. Akiyama, 'T. Hagio and A. Takase, Jpn. J. Appl. Phys., 34, 2344-49 (1995).

9) K. Nonaka, M. Akiyama, A. Takase, T. Baba, K. Yamamoto and H. Ito, J. Mater. Sci. Lett., 15, 2096-98 (1996).

10) K. Nonaka, M. Akiyama, A. Takase, T. Baba, K. Yamamoto and H. Ito, Jpn. J. Appl. Phys., 34, 5380-83 (1995).

11) M. Tanimura and K. Uchino, Sens. \& Mater., 1, 47-56 (1988).

12) K. Nonaka, A. Takase, T. Watanabe and H. Yoshida, "Ceramic Transactions, Vol. 43," Ed. by A. S. Bhalla, K. M. Nair, I. K. Lloyd, H. Yanagida and D. A. Payne, American Ceramic Society, Westerville (1994) pp. 295-99.

13) Y. Xu, "Ferroelectric Materials and Their Applications," North-Holland (1991) pp. 133-36.

14) V. V. Prisedsky, Ferroelectrics, 115, 81-89 (1991). 